\title{
Critical role of oncogenic KRAS in pancreatic cancer (Review)
}

\author{
JIANG LIU ${ }^{1-3}$, SHUNRONG JI ${ }^{1-3}$, CHEN LIANG $^{1-3}$, YI QIN ${ }^{1-3}$, KAIZHOU JIN ${ }^{1-3}$, DINGKON LIANG ${ }^{1-3}$, \\ WENYAN XU ${ }^{1-3}, \mathrm{SI} \mathrm{SHI}^{1-3}$, BO ZHANG ${ }^{1-3}$, LIANG LIU ${ }^{1-3}, \mathrm{CHEN} \mathrm{LIU}^{1-3}, \mathrm{JIN} \mathrm{XU}^{1-3}$, \\ QUANXING NI ${ }^{1-3}$ and XIANJUN YU ${ }^{1-3}$ \\ ${ }^{1}$ Department of Pancreatic Surgery, Shanghai Cancer Center, Fudan University; \\ ${ }^{2}$ Department of Oncology, Shanghai Medical College; ${ }^{3}$ Pancreatic Cancer Institute, \\ Fudan University, Shanghai 200032, P.R. China
}

Received November 26, 2015; Accepted April 14, 2016

DOI: $10.3892 / \mathrm{mmr} .2016 .5196$

\begin{abstract}
Pancreatic cancer is a human malignancy with one of the highest mortality rates and little progress has been achieved in its treatment in recent decades. Further improvement to the understanding of the biological and molecular mechanisms underlying the initiation and development of pancreatic ductal adenocarcinoma (PDAC) is required. Previous studies using genetically engineered mouse models have demonstrated that oncogenic GTPase KRas (KRAS) mutation is involved in the formation of pancreatic intraepithelial neoplasia and promotes the progression of PDAC. However, attempts to target KRAS directly by pharmacological inhibition have been unsuccessful. This has resulted in increased efforts to identify pharmacological targets and nodes associated with the mutated KRAS. The present review discusses the recent progress and prospects of KRAS signaling in pancreatic cancer.
\end{abstract}

\section{Contents}

1. Introduction

2. Initiation

3. Microenvironment

4. Metabolic reprogramming

5. Mouse model

6. Inhibitors

7. Summary

Correspondence to: Dr Xianjun Yu, Department of Pancreatic Surgery, Shanghai Cancer Center, Fudan University, 270 Dongan Road, Shanghai 200032, P.R. China

E-mail: yuxianjun@fudanpci.org

Key words: KRAS, pancreatic cancer, initiation, microenvironment, metabolic reprogramming, mouse models, inhibitors

\section{Introduction}

Pancreatic ductal adenocarcinoma (PDAC) is an incurable disease that results in mortality. The number of newly diagnosed cases almost equals the annual number of deaths despite advances in surgery and chemoradiotherapy in the past decades. Although the 5-year survival of pancreatic cancer patients has almost doubled over the past decade, it remains low at $7-8 \%$ according to the US National Cancer Institute (1). A lack of early diagnostic strategies, high resistance to chemoradiotherapy and early local or distant metastatic recurrence following surgery are the three predominant factors that contribute to poor outcomes. Further understanding of the biological and molecular mechanisms underlying the initiation and development of PDAC are required. Genetically, cancer progresses as a result of the combined activation of oncogenes and inactivation of tumor suppressors. Similarly, numerous molecular alterations are also required for pancreatic intraepithelial neoplasias (PanIN) lesions to develop into PDAC. Previous studies have established that PDAC is characterized by four signature mutations including mutations in GTPase KRas (KRAS) oncogene and in cyclin-dependent kinase inhibitor 2A (CDKN2A), tumor protein p53 (TP53), and SMAD family member 4 (SMAD4) tumor suppressor genes $(2,3)$. Approximately $90 \%$ of pancreatic neoplasms express mutant KRAS, which has been hypothesized to be the initiator of PDAC. However, the development of therapeutic agents targeting KRAS in PDAC remains unsuccessful. The present review discusses recent research regarding KRAS and explores potential therapeutic targets.

\section{Initiation}

PDAC develops with progressive cellular, morphological and architectural changes from normal ductal epithelium to preneoplastic lesions, and then PanINs and PDAC. The majority of PDAC and early PanIN lesions involve mutations in the KRAS oncogene. Almoguera et al (4) and Smit et al (5) first established the association between the mutant KRAS gene and PDAC in 1988. To investigate the role of the KRAS oncogene in the onset of PDAC, multiple genetically engineered mouse (GEM) models were established. The first model was the endogenous KRAS-based model, Ptf1a-Cre (6), followed 
by the Pdx1-Cre model (7). Pdx1-Cre;LSL-KRAS ${ }^{\mathrm{G} 12 \mathrm{D}}$ and Ptf1a-Cre;LSL-KRAS ${ }^{\mathrm{G} 12 \mathrm{D}}$ mice were also generated, these are generally referred to as $\mathrm{KC}$ mice (8) and express oncogenic KRAS from the earliest stage of pancreatic development. $\mathrm{KC}$ mice demonstrate that mutant KRAS is sufficient for the initiation of PDAC. The use of KC mice is a useful tool for pancreatic cancer research, as other signaling pathways and genetic events resulting in pancreatic carcinogenesis may be investigated (9). As tumor suppressor genes are usually lost or inactivated in human PDAC, $\mathrm{KC}$ mice have been crossed with mice with non-functional or mutant alleles of CDKN2A or p53 $(10,11)$. The latter model, usually referred to as KPC mice, is currently the most promising preclinical model of PDAC. When treated with standard therapeutic strategies for PDAC, KPC mice are observed to react in same way as human patients (12). PanIN with oncogenic KRAS is able to rapidly progress to PDAC when subjected to inflammatory insult (13).

\section{Microenvironment}

PDAC is a highly aggressive neoplasm that has a marked fibro-inflammatory microenvironment, promoting cancer induction and growth. GEM models have been used to investigate the role of KRAS on the PDAC microenvironment, which contains large quantities of inflammatory stroma. Immune cells infiltrate around the lowest grade preinvasive lesions, but immunosuppressive cells, including macrophages, regulatory $\mathrm{T}$ cells and myeloid-derived suppressor cells (MDSC), predominate in the early response and persist through invasive cancer (14). Phenotype changes of the stellate cells occur earlier than noticeable changes in other pancreatic components (15). Thus, even low levels of KRAS activity generate signals that influence the microenvironment.

By contrast to the majority of other solid tumors, pancreatic tumors are considered to be hypovascularized, although blood vessels are present within the tumor microenvironment as stellate cells produce angiogenic factors (16). In addition to the cellular components, the stroma comprises components of the extracellular matrix, including collagen fibers and hyaluronic acid $(17,18)$. Inactivation of KRAS also results in resolution of the chronic inflammation associated with pancreatic cancer. Thus, KRAS is hypothesized to regulate the production of factors that maintain an active stroma. These factors and their activities remain to be further elucidated, however, Sonic Hedgehog, interleukin-6 (IL-6), and prostaglandin E are considered factors, each of which is expressed in a KRAS-dependent manner (19). Sonic hedgehog (SHH) is one of the ligands of the hedgehog signaling pathway, it is expressed by pancreatic tumor cells $(20,21)$ and functions in a paracrine manner (22), activating hedgehog signaling in the stroma and potentially mediating its maintenance (23). The inflammatory cytokine IL-6 is overexpressed in pancreatic tumors and it important in the development of PanINs in mice (24). Prostaglandin E and prostaglandin E receptor 4 exert a direct effect on stellate cells to stimulate the production of stroma (19). All these factors are generated by sustained high-level KRAS activity.

The immune cells that infiltrate the pancreas also appear to be regulated by KRAS. In mouse models of PDAC, PanINs are infiltrated by immune cells, including those that suppress the immune response, including regulatory $\mathrm{T}$ cells, MDSC, and mast cells (25). Tumor cells secrete cytokines, such as granulocyte-macrophage colony-stimulating factor $(26,27)$, which further promotes infiltration of MDSC that inhibit anti-tumor immune responses. KRAS inactivation results in an overall reduction in the number of infiltrating immune cells. Thus, the inflammatory environment of pancreatic tumors also appears to be regulated by KRAS in a paracrine manner, forming part of a KRAS-associated positive-feedback loop of inflammation that requires further elucidation in the future.

Chronic inflammation is known to be a risk factor of pancreatic cancer (28). Although the mechanism is not entirely understood, sustained inflammation contributes to a compromised anti-tumor immune response via the infiltration of immunosuppressive regulatory T cells and MDSC $(29,30)$. In addition, these inflammatory stimuli activate stellate cells and fibroblasts, leading to fibrotic remodeling of the pancreatic tissue, which in turn enhances oncogenic KRAS signaling (29). Neoplastic changes occur under pancreatic inflammation when adult murine pancreas express oncogenic KRAS (31). Thus, oncogenic KRAS signaling is enhanced by inflammatory stimuli, and enhances inflammation and desmoplasia in pancreatic neoplasia.

In addition to intracellular factors, the interactions between the tumor cells and their microenvironment are also controlled by KRAS, although the mechanisms require further elucidation. In iKRAS mice, inactivation of oncogenic KRAS at any stage of carcinogenesis results in reduced proliferation and smooth muscle actin expression in the stroma (32). $\mathrm{SHH}$, secreted by tumor cells, is one of the signals mediating the interaction between the tumor cells and the surrounding fibroblasts within the stroma $(20,21)$, and it also activates paracrine signaling in fibroblasts (22). However, it is probable that additional signals are involved in the regulation of the interactions between KRAS-expressing epithelial cells and the surrounding microenvironment. Oncogenic KRAS mutations and the immune microenvironment may act synergistically to promote the development and progression of PDAC.

\section{Metabolic reprogramming}

In 1956, Warburg (33) recognized that altered metabolism is a characteristic of cancer. By contrast to normal cells, tumor cells metabolize $\sim 10$ times more glucose than lactate, a phenomenon now referred to as aerobic glycolysis or the Warburg effect.

KRAS is key in metabolic reprogramming, particularly in the glycolytic switch (34-37). Oncogenic KRAS was recently demonstrated to regulate metabolic changes in pancreatic cancer cells by increasing the expression of glycolytic enzymes, including hexokinase 1 and 2, glucose transporter 1, phosphofructokinase 1 and lactate dehydrogenase A (38). KRAS also supports biomass synthesis, of proteins and nucleic acids, and fatty acid synthesis required for pancreatic cancer cell proliferation via stimulation of glucose uptake and channeling of glucose intermediates into the hexosamine biosynthesis and pentose phosphate pathway (38).

Transcriptional reprogramming of key metabolic enzymes (for example glutamate dehydrogenase-1 and glutamic-oxaloacetic transaminase 1) in the glutamine 


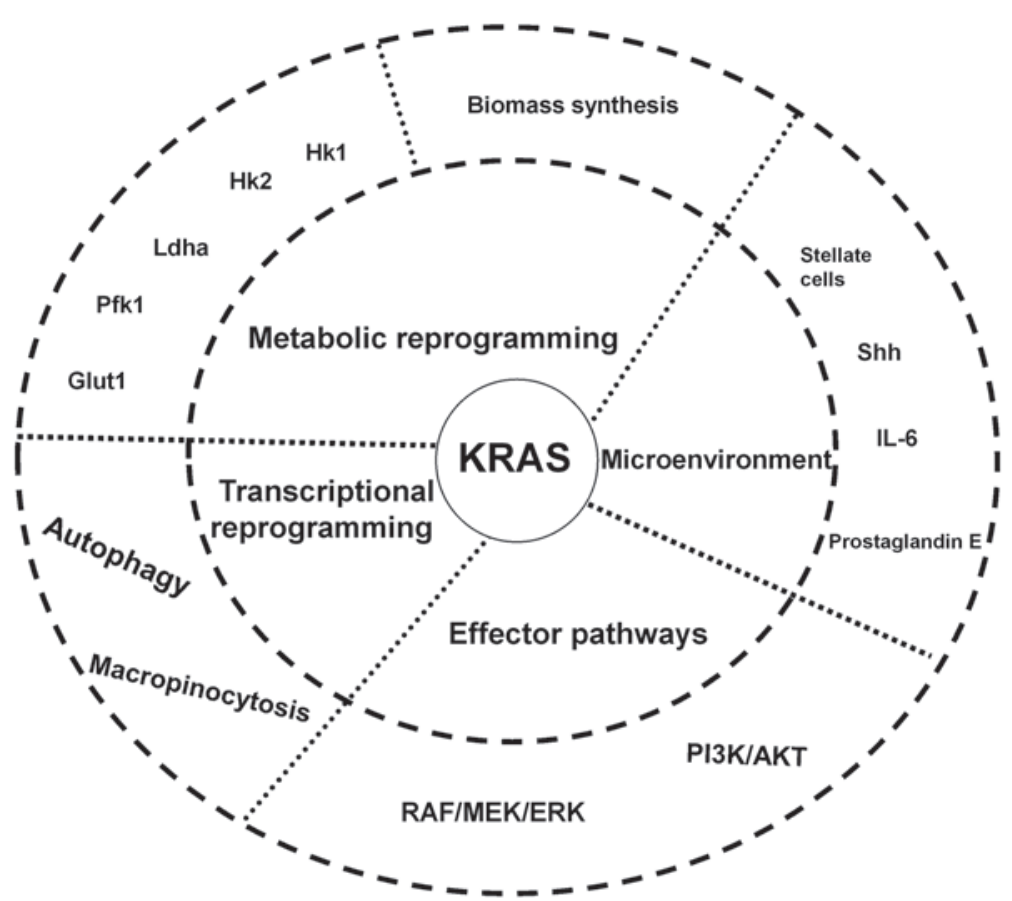

Figure 1. Large number of signaling pathways involving oncogenic KRAS is critical in pancreatic cancer cell proliferation, apoptosis, invasion and metastasis. KRAS, GTPase KRas; Shh, sonic hedgehog; Hk1, hexokinase 1; Hk2, hexokinase 2; Glut1, glucose transporter 1; Pfk1, phosphofructokinase 1; Ldha, lactate dehydrogenase A; IL-6, interleukin 6; PI3K, phosphatidylinositol-4,5-bisphosphate 3-kinase.

pathway, which is involved in the utilization of autophagy in PDAC, is driven by KRAS $(39,40)$. Inhibition of autophagy in mouse models blocked KRAS tumorigenicity in a wild-type TP53 background, but resulted in PanIN transformation into invasive PDAC in the presence of an oncogenic KRAS mutation and a TP53 deletion (41). KRAS has an additional role in absorbing and degrading the extracellular components of cancer cells, referred to as macropinocytosis. Upregulation of macropinocytosis by KRAS contributes to the metabolic requirements of PDAC cell lines, however, inhibition of macropinocytosis results in slowing of KRAS-transformed cell growth $(42,43)$. Thus, it may be possible to design therapeutic agents to target KRAS, or its effectors, that alter pancreatic cancer metabolism and impair the ability of the cancer cells to maintain high levels of glycolysis (44).

\section{Mouse model}

Cancer-associated mortality is predominantly due to a lack of early diagnosis and effective therapeutic strategies. However, the underlying molecular mechanisms of PDAC development and progression are little known, thus, the development of mouse models is required, particularly GEM models, to investigate the mechanisms of pancreatic tumorigenesis and reproduce the pathogenesis of PDAC to aid development of diagnostic and therapeutic strategies.

Prenatal mouse models. The expression of a resident KRAS ${ }^{\mathrm{G} 12 \mathrm{D}}$ oncogene during early embryonic development was used in the first mouse model that demonstrated natural pathogenesis of human PDAC in mice (7). Briefly, a resident $\mathrm{KRAS}^{\mathrm{G} 12 \mathrm{D}}$ mouse strain was crossed with transgenic strains that expressed the bacterial Cre recombinase under control of Pdx1 (Pdx1-Cre) or Ptfla (Ptfla-Cre), silencing was conducted using a floxed STOP transcriptional cassette (LSL-KRAS ${ }^{\mathrm{G} 12 \mathrm{D}}$ ) to produce Pdx1-Cre;LSL-KRAS ${ }^{\text {G12D }}$ and Ptf1a-Cre;LSL-KRAS ${ }^{\text {G12D }}$, which express the KRAS ${ }^{\mathrm{G} 12 \mathrm{D}}$ oncogene in all pancreatic lineages. Thus, a full series of PanIN lesions that are histologically the same with those in human patients were developed. Mucins, cytokeratin-19, and components of signaling pathways including cyclooxygenase-2, epidermal grow th factor receptor, matrix metalloproteinase-7 and transcription factor Hes1 are also expressed in these mouse PanINs (45). There is a long latent period between PanIN lesions and PDAC in a certain percentage of mice. However, induction of mutations observed in human PDAC, including CDKN2A, TP53, liver kinase B1 (LKB1) or SMAD4 resulted in accelerated progression from PanIN lesions to invasive PDAC, a number of the mice also develop metastatic tumors. In recent reviews, the majority of the important GEM PDAC models have been summarized (46-49).

Notch signaling pathways are important in the progression of pancreatic cancer, which has been investigated in GEM models. Deletion of Notch-1 resulted in an increased tumor incidence and progression in Pdx-1-Cre;LSL-KRAS ${ }^{\text {G12D }}$ mice, indicating that Notch-1 may be a tumor suppressor gene in pancreatic cancer development (50). However, another previous study demonstrated that deficiency of Notch-2, but not Notch-1, blocked PanIN progression and prolonged survival (51). These findings suggest further investigation into the exact physiological role of Notch-1 in pancreatic cancer initiation and progression is required.

Postnatal mouse models. Though numerous similarities are observed between the PanIN lesions and PDAC in GEM models and those of human patients, the etiology is distinct. 
PDAC is not a pediatric disease, which indicates PDAC tumors are more likely to arise as a result of sporadic mutations in adult individuals. In addition, KRAS mutations are not exhibited by the entire pancreas but in certain PDAC cell types. To begin to address these issues, a second generation of GEM models was generated by crossing mice with a resident KRASLSLG12Vgeo allele with double transgenic mice (Elas-tTA;Tet-O-Cre). During late embryonic development, these composite mice express the knocked-in KRASG12 V oncogene in $20-30 \%$ of acinar cells (31). Notably, the latent period and penetrance of PanIN lesion development are similar to those expressing the KRAS ${ }^{\mathrm{G} 12 \mathrm{D}}$ oncogene. The above model enables expression of KRAS oncogene to be activated in a controlled temporal manner by feeding the mice with doxycycline (52).

In PDAC, serine/threonine-protein kinase B-raf (BRAF) or phosphatidylinositol-4,5-bisphosphate 3-kinase, catalytic subunit $\alpha$ (PIK3CA) activation is uncommon (53). However, GEM models with BRAF or PIK3CA mutations may provide key information to aid understanding of PDAC development. For example, the expression of the BRAF V600E mutation in early pancreatic precursors results in embryonic lethality. However, in P14 mice that express the same BRAF V600E mutation, activation of the Pdx1-CreERT2 (estrogen receptor 2) transgene by exposure to tamoxifen results in widespread PanIN development (54). Notably, these PanINs did not progress to PDAC tumors within one year. However, with the same Pdx1-CreERT2 transgene, activation of the PIK3CA H1047R oncogene did not induce any PanIN lesions. This suggests that it is the RAF/mitogen-activated protein kinase kinase (MEK)/extracellular signal-regulated kinase (ERK) signaling pathway activated when KRAS oncogenes initiate PanIN lesions rather than the phosphatidylinositol-4,5-bisphosphate 3-kinase (PI3K)/AKT signaling pathway. This indicates the importance of the RAF/MEK/ERK signaling pathway in tumor initiation and maintenance. Furthermore, future therapeutic strategies may be developed to target it.

Hereditary mouse models. Among patients with pancreatic cancer, $\sim 10 \%$ have a family history of the disease. There is a 2 times greater risk of pancreatic cancer when a first-degree relative is diagnosed. Families carrying germline mutations in certain genes, including breast cancer 2, early onset (BRCA2), CDKN2A, LKB1, protease serine 1 and partner and localizer of BRCA2 also have an increased risk (55). Through mixing the $\mathrm{KC}$ strain of mice with mice with a truncated BRCA2 gene, two GEM models for hereditary pancreatic cancer have been produced. PDAC formed in these mice with high penetrance and a shorter latency period compared with those carrying wild-type BRCA2 alleles (56). However, in a similar study, a KRAS ${ }^{\mathrm{G} 12 \mathrm{D}}$-background mouse with BRCA2 homozygously inactivated developed acinar carcinoma, not PDAC (57). The KC mouse model with a conditional floxed LKB1 allele also resulted in an increased number of PanINs, and complete penetrance and shorter latency of PDAC tumor formation (58). Notably, where the KRAS oncogene is not observed, homozygous loss of BRCA2 or LKB1 has different results in early pancreatic precursors. Pdx1-Cre;LKB1lox/lox mice have very short latency periods prior to development of pancreatic mucinous cystadenomas (58), though knockout of BRCA2 does not induce histological alterations (57). These observations suggest that there are a variety of methods to control the malignant transformation of pancreatic cells.

Other mouse models. In 1985, Hanahan (59) described the widely used RIP-Tag model, which is an important GEM model of pancreatic endocrine tumor. Models of intraductal papillary mucinous neoplasms (IPMNs) and mucinous cystic neoplasms (MCNs) were also later developed. For example, in the pancreas of $\mathrm{KC}$ mice, $\mathrm{Smad} 4$ deletion was observed to induce the development of IPMNs and MCNs $(60,61)$. These cystic preneoplasms, if not resected, have the potential to progress to invasive PDAC. In 2007, Siveke et al (62) indicated that co-expression of transforming growth factor (TGF)- $\alpha$ and KRAS ${ }^{\mathrm{G} 12 \mathrm{D}}$ results in the development of cystic papillary neoplasms similar to IPMNs. Furthermore, deletion of the transcriptional intermediary factor- $1 \gamma$, which is thought to be involved in TGF- $\beta$ signaling in pancreatic progenitor cells, with KRAS ${ }^{\text {G12D }}$ induced IPMNs (63). These GEM models illustrate that the PanINs and cystic neoplasms that progress to PDAC are associated with alterations in the TGF- $\alpha$ and TGF- $\beta$ signaling pathways.

\section{Inhibitors}

The KRAS gene has been demonstrated to be important in the development of PDAC, demonstrating the development of KRAS inhibitors is required. Blocking the KRAS GTP binding site directly prevents KRAS signaling. However, effective therapies that directly target mutated KRAS remain unavailable, thus, research has focused on targeting KRAS indirectly. Farnesylated KRAS following translation is translocated to the membrane and the Ras-activating proteins located there. It is then activated by guanine nucleotide exchange factors (Ras-GEFs). Farnesyltransferase inhibitors (FTIs) are important in the post-translational modification of KRAS activation. Certain FTIs, including lonafarnib and tipifarnib, have been tested clinically tested, though the results are not yet satisfactory in treating KRAS-driven tumors (64). This failure may be due to the three different types of Ras proteins.

The majority of successful results of FTIs in preclinical studies have focused on GTPase HRas (HRAS)-dependent tumors (65). Compared with HRAS, KRAS may be geranylgeranylated by inhibiting farnesyltransferase (66). Via the alternate post-translational modification of farnesylation, KRAS may be localized to the membrane and so be activated. This has led to the development of potential therapeutic strategies to prevent KRAS reaching the membrane. Deltarasin is an inhibitor that binds to the farnesyl-binding pocket of phosphodiesterase (PDE) (67). Following farnesylation, KRAS interacts with PDE and is translocated to the membrane (68). Salirasib is another inhibitor that limit KRAS activity in the membrane. Unlike PDE, Salirasib removes the farnesylated protein from the membrane, thus blocking KRAS activity (69). Salirasib has shown potential as a KRAS inhibitor in preclinical and clinical trials against PDAC (70).

When KRAS cannot be blocked from reaching the membrane, other therapeutic strategies are required to prevent activation of KRAS on the membrane. Patgiri et al (71) 
designed a small-molecule $\alpha$-helix mimic, using the hydrogen bond surrogate, to block the exchange of GDP for GTP, and thus inhibit the interaction between KRAS and its Ras-GEF SOS. Post-translational acetylation of KRAS alters the ability of SOS to exchange GDP for GTP, however, further research is required to elucidate the role acetylation has in the activity of mutant KRAS.

The RAF/MEK/ERK and PI3K/AKT signaling pathways are the targets of an increasing amount of research and numerous inhibitors targeting these signaling pathways are already being tested in clinical trials. In KRAS ${ }^{\mathrm{G} 12 \mathrm{D}}$-driven GEM models, inhibition of PI3K signaling has been demonstrated to be efficient at inhibiting growth in vivo (72). Inhibition of MEK1/2 has demonstrated suppression of cell growth in cell lines of orthotopically transplanted human and mouse PDAC. Preclinical studies of non-small cell lung cancer (NSCLC) have also demonstrated successful results for this potential therapy (73).

Dual-pathway inhibition has demonstrated promising results, however, its toxicity is markedly higher than single-agent therapy (74). To ameliorate this, tissue-specific effectors required for the activation of the two signaling pathways should be targeted. In preclinical studies of NSCLC, Molina-Arcas et al (75) demonstrated dual-pathway inhibition via inhibiting IGF1R and MEK. However, further investigation is required to determine the efficacy of dual signaling pathway inhibition against KRAS-driven PDAC.

\section{Summary}

Although oncogenic KRAS has been associated with PDAC for over 20 years, pharmacological attempts to target KRAS directly have been unsuccessful. Single downstream effector inhibition may only be modestly effective as oncogenic KRAS activates multiple downstream signaling pathways (Fig. 1). More studies are required to further elucidate the underlying mechanisms of PDAC initiation and progression. Comprehensive investigation into PDAC may provide potential therapeutic strategies against pancreatic cancer for the future.

\section{Acknowledgements}

The present review was supported by the National Natural Science Foundation (grant nos. 81372651, 81201900, 81172276 and 81101565), and the Sino-German Center (grant. no. GZ857).

\section{References}

1. National Cancer Institute: SEER stat fact sheets, pancreas. http:// seer.cancer.gov/statfacts/html/pancreas.html. Accessed April 15, 2016.

2. Vogelstein B, Papadopoulos N, Velculescu VE, Zhou S, Diaz LA Jr and Kinzler KW: Cancer genome landscapes. Science 339: 1546-1558, 2013.

3. Wood LD and Hruban RH: Pathology and molecular genetics of pancreatic neoplasms. Cancer J 18: 492-501, 2012.

4. Almoguera C, Shibata D, Forrester K, Martin J, Arnheim N and Perucho M: Most human carcinomas of the exocrine pancreas contain mutant c-K-ras genes. Cell 53: 549-554, 1988.

5. Smit VT, Boot AJ, Smits AM, Fleuren GJ, Cornelisse CJ and Bos JL: KRAS codon 12 mutations occur very frequently in pancreatic adenocarcinomas. Nucleic Acids Res 16: 7773-7782, 1988.
6. Kawaguchi Y, Cooper B, Gannon M, Ray M, MacDonald RJ and Wright CV: The role of the transcriptional regulator Ptfla in converting intestinal to pancreatic progenitors. Nat Genet 32: $128-134,2002$

7. Hingorani SR, Petricoin EF, Maitra A, Rajapakse V, King C, Jacobetz MA, Ross S, Conrads TP, Veenstra TD, Hitt BA, et al: Preinvasive and invasive ductal pancreatic cancer and its early detection in the mouse. Cancer Cell 4: 437-450, 2003.

8. Olive KP and Tuveson DA: The use of targeted mouse models for preclinical testing of novel cancer therapeutics. Clin Cancer Res 12: 5277-5287, 2006.

9. Morris JP IV, Wang SC and Hebrok M: KRAS, Hedgehog, Wnt and the twisted developmental biology of pancreatic ductal adenocarcinoma. Nat Rev Cancer 10: 683-695, 2010.

10. Aguirre AJ, Bardeesy N, Sinha M, Lopez L, Tuveson DA, Horner J, Redston MS and DePinho RA: Activated KRAS and Ink4a/Arf deficiency cooperate to produce metastatic pancreatic ductal adenocarcinoma. Genes Dev 17: 3112-3126, 2003.

11. Hingorani SR, Wang L, Multani AS, Combs C, Deramaudt TB, Hruban RH, Rustgi AK, Chang S and Tuveson DA: Trp53R172H and KRASG12D cooperate to promote chromosomal instability and widely metastatic pancreatic ductal adenocarcinoma in mice. Cancer Cell 7: 469-483, 2005.

12. Singh M, Lima A, Molina R, Hamilton P, Clermont AC, Devasthali V, Thompson JD, Cheng JH, Bou Reslan H, Ho CC, et al: Assessing therapeutic responses in KRAS mutant cancers using genetically engineered mouse models. Nat Biotechnol 28: 585-593, 2010.

13. Carrière C, Young AL, Gunn JR, Longnecker DS and Korc M: Acute pancreatitis accelerates initiation and progression to pancreatic cancer in mice expressing oncogenic KRAS in the nestin cell lineage. PLoS One 6: e27725, 2011.

14. Clark CE, Hingorani SR, Mick R, Combs C, Tuveson DA and Vonderheide RH: Dynamics of the immune reaction to pancreatic cancer from inception to invasion. Cancer Res 67: 9518-9527, 2007.

15. Won JH, Zhang Y, Ji B, Logsdon CD and Yule DI: Phenotypic changes in mouse pancreatic stellate cell $\mathrm{Ca} 2+$ signaling events following activation in culture and in a disease model of pancreatitis. Mol Biol Cell 22: 421-436, 2011.

16. Erkan M, Adler G, Apte MV, Bachem MG, Buchholz M, Detlefsen S, Esposito I, Friess H, Gress TM, Habisch HJ, et al: StellaTUM: Current consensus and discussion on pancreatic stellate cell research. Gut 61: 172-178, 2012.

17. Jacobetz MA, Chan DS, Neesse A, Bapiro TE, Cook N, Frese KK, Feig C, Nakagawa T, Caldwell ME, Zecchini HI, et al: Hyaluronan impairs vascular function and drug delivery in a mouse model of pancreatic cancer. Gut 62: 112-120, 2013.

18. Provenzano PP, Cuevas C, Chang AE, Goel VK, Von Hoff DD and Hingorani SR: Enzymatic targeting of the stroma ablates physical barriers to treatment of pancreatic ductal adenocarcinoma. Cancer Cell 21: 418-429, 2012.

19. Charo C, Hwang RF, Arumugam T, Hwang R, Yang P, Dubois RN, Menter DG, Logsdon CD and Ramachandran V: Prostaglandin E2 regulates pancreatic stellate cell activity via the EP4 receptor. Pancreas 42: 467-474, 2013.

20. Thayer SP, di Magliano MP, Heiser PW, Nielsen CM, Roberts DJ, Lauwers GY, Qi YP, Gysin S, Fernández-del Castillo C, Yajnik V, et al: Hedgehog is an early and late mediator of pancreatic cancer tumorigenesis. Nature 425: 851-856, 2003.

21. Berman DM, Karhadkar SS, Maitra A, Montes De Oca R, Gerstenblith MR, Briggs K, Parker AR, Shimada Y, Eshleman JR, Watkins DN and Beachy PA: Widespread requirement for hedgehog ligand stimulation in growth of digestive tract tumours. Nature 425: 846-851, 2003.

22. Yauch RL, Gould SE, Scales SJ, Tang T, Tian H, Ahn CP, Marshall D, Fu L, Januario T, Kallop D, et al: A paracrine requirement for hedgehog signalling in cancer. Nature 455: 406-410, 2008

23. Olive KP, Jacobetz MA, Davidson CJ, Gopinathan A, McIntyre D, Honess D, Madhu B, Goldgraben MA, Caldwell ME, Allard D, et al: Inhibition of hedgehog signaling enhances delivery of chemotherapy in a mouse model of pancreatic cancer. Science 324: 1457-1461, 2009.

24. Lesina M, Kurkowski MU, Ludes K, Rose-John S, Treiber M, Klöppel G, Yoshimura A, Reindl W, Sipos B, Akira S, et al: Stat $3 /$ Socs 3 activation by IL- 6 transsignaling promotes progression of pancreatic intraepithelial neoplasia and development of pancreatic cancer. Cancer Cell 19: 456-469, 2011. 
25. Chang DZ, Ma Y, Ji B, Wang H, Deng D, Liu Y, Abbruzzese JL, Liu YJ, Logsdon CD and Hwu P: Mast cells in tumor microenvironment promotes the in vivo growth of pancreatic ductal adenocarcinoma. Clin Cancer Res 17: 7015-7023, 2011.

26. Pylayeva-Gupta Y, Lee KE, Hajdu CH, Miller G and Bar-Sagi D: Oncogenic KRAS-induced GM-CSF production promotes the development of pancreatic neoplasia. Cancer Cell 21: 836-847, 2012.

27. Bayne LJ, Beatty GL, Jhala N, Clark CE, Rhim AD, Stanger BZ and Vonderheide RH: Tumor-derived granulocyte-macrophage colony-stimulating factor regulates myeloid inflammation and T cell immunity in pancreatic cancer. Cancer Cell 21: 822-835, 2012.

28. Yadav D and Lowenfels AB: The epidemiology of pancreatitis and pancreatic cancer. Gastroenterology 144: 1252-1261, 2013.

29. Pylayeva-Gupta Y, Grabocka E and Bar-Sagi D: RAS oncogenes: Weaving a tumorigenic web. Nat Rev Cancer 11: 761-774, 2011

30. Steele CW, Jamieson NB, Evans TR, McKay CJ, Sansom OJ, Morton JP and Carter CR: Exploiting inflammation for therapeutic gain in pancreatic cancer. Br J Cancer 108: 997-1003, 2013.

31. Guerra C, Schuhmacher AJ, Cañamero M, Grippo PJ, Verdaguer L, Pérez-Gallego L, Dubus P, Sandgren EP and Barbacid M: Chronic pancreatitis is essential for induction of pancreatic ductal adenocarcinoma by K-Ras oncogenes in adult mice. Cancer Cell 11: 291-302, 2007.

32. Collins MA, Bednar F, Zhang Y, Brisset JC, Galbán S, Galbán CJ, Rakshit S, Flannagan KS, Adsay NV and Pasca di Magliano M: Oncogenic Kras is required for both the initiation and maintenance of pancreatic cancer in mice. J Clin Invest 122: 639-653, 2012.

33. Warburg O: On the origin of cancer cells. Science 123: 309-314, 1956.

34. Feldmann G, Beaty R, Hruban RH and Maitra A: Molecular genetics of pancreatic intraepithelial neoplasia. J Hepatobiliary Pancreat Surg 14: 224-232, 2007.

35. Gaglio D, Metallo CM, Gameiro PA, Hiller K, Danna LS, Balestrieri C, Alberghina L, Stephanopoulos G and Chiaradonna F: Oncogenic K-Ras decouples glucose and glutamine metabolism to support cancer cell growth. Mol Syst Biol 7: 523, 2011

36. Dell'Antone P: Energy metabolism in cancer cells: How to explain the Warburg and Crabtree effects? Med Hypotheses 79: 388-392, 2012

37. Bryant KL, Mancias JD, Kimmelman AC and Der CJ: KRAS: Feeding pancreatic cancer proliferation. Trends Biochem Sci 39: 91-100, 2014.

38. Ying H, Kimmelman AC, Lyssiotis CA, Hua S, Chu GC, Fletcher-Sananikone E, Locasale JW, Son J, Zhang H, Coloff JL, et al: Oncogenic Kras maintains pancreatic tumors through regulation of anabolic glucose metabolism. Cell 149: 656-670, 2012

39. Wise DR, DeBerardinis RJ, Mancuso A, Sayed N, Zhang XY, Pfeiffer HK, Nissim I, Daikhin E, Yudkoff M, McMahon SB and Thompson CB: Myc regulates a transcriptional program that stimulates mitochondrial glutaminolysis and leads to glutamine addiction. Proc Natl Acad Sci USA 105: 18782-18787, 2008.

40. Son J, Lyssiotis CA, Ying H, Wang X, Hua S, Ligorio M, Perera RM, Ferrone CR, Mullarky E, Shyh-Chang N, et al: Glutamine supports pancreatic cancer growth through a KRAS-regulated metabolic pathway. Nature 496: 101-105, 2013.

41. Rosenfeldt MT, O'Prey J, Morton JP, Nixon C, MacKay G, Mrowinska A, Au A, Rai TS, Zheng L, Ridgway R, et al: p53 status determines the role of autophagy in pancreatic tumour development. Nature 504: 296-300, 2013.

42. Kamphorst JJ, Cross JR, Fan J, de Stanchina E, Mathew R, White EP, Thompson CB and Rabinowitz JD: Hypoxic and Ras-transformed cells support grow th by scavenging unsaturated fatty acids from lysophospholipids. Proc Natl Acad Sci USA 110: 8882-8887, 2013

43. Commisso C, Davidson SM, Soydaner-Azeloglu RG, Parker SJ, Kamphorst JJ, Hackett S, Grabocka E, Nofal M, Drebin JA, Thompson CB, et al: Macropinocytosis of protein is an amino acid supply route in Ras-transformed cells. Nature 497: 633-637, 2013.

44. Neesse A, Michl P, Frese KK, Feig C, Cook N, Jacobetz MA, Lolkema MP, Buchholz M, Olive KP, Gress TM and Tuveson DA: Stromal biology and therapy in pancreatic cancer. Gut 60: $861-868,2011$
45. Zhu L, Shi G, Schmidt CM, Hruban RH and Konieczny SF Acinar cells contribute to the molecular heterogeneity of pancreatic intraepithelial neoplasia. Am J Pathol 171: 263-273, 2007.

46. Mazur PK and Siveke JT: Genetically engineered mouse models of pancreatic cancer: Unravelling tumour biology and progressin translational oncology. Gut 61: 1488-1500, 2012.

47. Pérez-Mancera PA, Guerra C, Barbacid M and Tuveson DA What we have learned about pancreatic cancer from mouse models. Gastroenterology 142: 1079-1092, 2012.

48. Qiu W and Su GH: Challenges and advances in mouse modeling for human pancreatic tumorigenesis and metastasis. Cancer Metastasis Rev 32: 83-107, 2013.

49. Westphalen CB and Olive KP: Genetically engineered mouse models of pancreatic cancer. Cancer J 18: 502-510, 2012

50. Hanlon L, Avila JL, Demarest RM, Troutman S, Allen M, Ratti F, Rustgi AK, Stanger BZ, Radtke F, Adsay V, et al: Notch1 functions as a tumor suppressor in a model of K-ras-induced pancreatic ductal adenocarcinoma. Cancer Res 70: 4280-4286, 2010.

51. Mazur PK, Einwächter H, Lee M, Sipos B, Nakhai H, Rad R, Zimber-Strobl U, Strobl LJ, Radtke F, Klöppel G, et al: Notch2 is required for progression of pancreatic intraepithelial neoplasia and development of pancreatic ductal adenocarcinoma. Proc Nat Acad Sci USA 107: 13438-13443, 2010.

52. Guerra C, Collado M, Navas C, Schuhmacher AJ, Hernández-Porras I, Cañamero M, Rodriguez-Justo $\mathrm{M}$, Serrano $\mathrm{M}$ and Barbacid M: Pancreatitis-induced inflammation contributes to pancreatic cancer by inhibiting oncogene induced senescence. Cancer Cell 19: 728-739, 2011.

53. Jones S, Zhang X, Parsons DW, Lin JC, Leary RJ, Angenendt P, Mankoo P, Carter H, Kamiyama H, Jimeno A, et al: Core signaling pathways in human pancreatic cancers revealed by global genomic analyses. Science 321: 1801-1806, 2008.

54. Collisson EA, Trejo CL, Silva JM, Gu S, Korkola JE, Heiser LM, Charles RP, Rabinovich BA, Hann B, Dankort D, et al: A central role for RAF-MEK-ERK signaling in the genesis of pancreatic ductal adenocarcinoma. Cancer Discov 2: 685-693, 2012.

55. Hruban RH, Canto M, Goggins M, Schulick R and Klein AP: Update on familial pancreatic cancer. Adv Surg 44: 293-311, 2010.

56. Skoulidis F, Cassidy LD, Pisupati V, Jonasson JG, Bjarnason H, Eyfjord JE, Karreth FA, Lim M, Barber LM, Clatworthy SA, et al: Germline Brca2 heterozygosity promotes Kras (G12D)-driven carcinogenesis in a murine model of familial pancreatic cancer. Cancer Cell 18: 499-509, 2010.

57. Rowley M, Ohashi A, Mondal G, Mills L, Yang L, Zhang L, Sundsbak R, Shapiro V, Muders MH, Smyrk T and Couch FJ: Inactivation of Brca 2 promotes Trp53-associated but inhibits KrasG12D-dependent pancreatic cancer development in mice. Gastroenterology 140: 1303-1313.e1-e3, 2011.

58. Morton JP, Jamieson NB, Karim SA, Athineos D, Ridgway RA, Nixon C, McKay CJ, Carter R, Brunton VG, Frame MC, et al: LKB1 haploinsufficiency cooperates with Kras to promote pancreatic cancer through suppression of p21-dependent growth arrest. Gastroenterology 139: 586-597.e1-e6, 2010.

59. Hanahan D: Heritable formation of pancreatic beta-cell tumours in transgenic mice expressing recombinant insulin/simian virus 40 oncogenes. Nature 315: 115-122, 1985

60. Bardeesy N, Cheng KH, Berger JH, Chu GC, Pahler J, Olson P, Hezel AF, Horner J, Lauwers GY, Hanahan D and DePinho RA: Smad4 is dispensable for normal pancreas development yet critical in progression and tumor biology of pancreas cancer. Genes Dev 20: 3130-3146, 2006.

61. Izeradjene K, Combs C, Best M, Gopinathan A, Wagner A, Grady WM, Deng CX, Hruban RH, Adsay NV, Tuveson DA and Hingorani SR: Kras (G12D) and Smad4/Dpc4 haploinsufficiency cooperate to induce mucinous cystic neoplasms and invasive adenocarcinoma of the pancreas. Cancer Cell 11: 229-243, 2007.

62. Siveke JT, Lubeseder-Martellato C, Lee M, Mazur PK, Nakhai H, Radtke F and Schmid RM: Notch signaling is required for exocrine regeneration after acute pancreatitis. Gastroenterology 134: 544-555, 2008.

63. Vincent DF, Yan KP, Treilleux I, Gay F, Arfi V, Kaniewski B, Marie JC, Lepinasse F, Martel S, Goddard-Leon S, et al: Inactivation of TIF1gamma cooperates with Kras to induce cystic tumors of the pancreas. PLoS Genet 5: e1000575, 2009.

64. Appels NM, Beijnen JH and Schellens JH: Development of farnesyl transferase inhibitors: A review. Oncologist 10: 565-578, 2005. 
65. Kohl NE, Omer CA, Conner MW, Anthony NJ, Davide JP, deSolms SJ, Giuliani EA, Gomez RP, Graham SL, Hamilton K, et al: Inhibition of farnesyltransferase induces regression of mammary and salivary carcinomas in ras transgenic mice. Nat Med 1: 792-797, 1995.

66. Whyte DB, Kirschmeier P, Hockenberry TN, Nunez-Oliva I, James L, Catino JJ, Bishop WR and Pai JK: K- and N-Ras are geranylgeranylated in cells treated with farnesyl protein transferase inhibitors. J Biol Chem 272: 14459-14464, 1997.

67. Zimmermann G, Papke B, Ismail S, Vartak N, Chandra A Hoffmann M, Hahn SA, Triola G, Wittinghofer A, Bastiaens PI and Waldmann H: Small molecule inhibition of the KRAS-PDES interaction impairs oncogenic KRAS signalling. Nature 497: 638-642, 2013

68. Chandra A, Grecco HE, Pisupati V, Perera D, Cassidy L, Skoulidis F, Ismail SA, Hedberg C, Hanzal-Bayer M, Venkitaraman AR, et al: The GDI-like solubilizing factor PDES sustains the spatial organization and signalling of Ras family proteins. Nat Cell Biol 14: 148-158, 2011.

69. Weisz B, Giehl K, Gana-Weisz M, Egozi Y, Ben-Baruch G, Marciano D, Gierschik P and Kloog Y: A new functional Ras antagonist inhibits human pancreatic tumor growth in nude mice. Oncogene 18: 2579-2588, 1999.
70. Laheru D, Shah P, Rajeshkumar NV, McAllister F, Taylor G, Goldsweig H, Le DT, Donehower R, Jimeno A, Linden S, et al: Integrated preclinical and clinical development of S-trans, trans-Farnesylthiosalicylic Acid (FTS, Salirasib) in pancreatic cancer. Invest New Drugs 30: 2391-2399, 2012

71. Patgiri A, Yadav KK, Arora PS and Bar-Sagi D: An orthosteric inhibitor of the Ras-Sos interaction. Nat Chem Biol 7: 585-587, 2011.

72. Eser S, Reiff N, Messer M, Seidler B, Gottschalk K, Dobler M, Hieber M, Arbeiter A, Klein S, Kong B, et al: Selective requirement of PI3K/PDK1 signaling for Kras oncogene-driven pancreatic cell plasticity and cancer. Cancer Cell 23: 406-420, 2013.

73. Engelman JA: Targeting PI3K signalling in cancer: Opportunities, challenges and limitations. Nat Rev Cancer 9: 550-562, 2009.

74. Shimizu T, Tolcher AW, Papadopoulos KP, Beeram M, Rasco DW, Smith LS, Gunn S, Smetzer L, Mays TA, Kaiser B, et al: The clinical effect of the dual-targeting strategy involving PI3K/AKT/mTOR and RAS/MEK/ERK pathways in patients with advanced cancer. Clin Cancer Res 18: 2316-2325, 2012.

75. Molina-Arcas M, Hancock DC, Sheridan C, Kumar MS and Downward J: Coordinate direct input of both KRAS and IGF1 receptor to activation of PI3 kinase in KRAS-mutant lung cancer. Cancer Discov 3: 548-563, 2013. 